\title{
The human genome project will not replace the physician
}

\section{Charles R. Scriver}

Dr. Scriver has graciously allowed us to to adapt his keynote lecture given at the annual meeting of the Canadian Paediatric Society in Montréal on June 17, 2004, for this article.

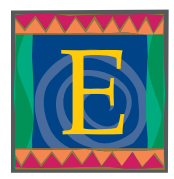

very physician interprets manifestations of illness. Osler, more than anyone, was the first to move medical practice beyond the level of a trade and give it an intellectual foundation and language. Osler interpreted the manifestations of disease with a vocabulary of signs and symptoms that gave logic to diagnosis and treatment. He knew that clinical manifestations were reflections of a deviant process, which he called pathogenesis. Histology, physiology and pathology (the "Institutes of Medicine," as he called them), along with microbiology and, later, cell biology, would provide the syntax of pathogenesis. To know the cause of the disease would reveal the deep grammar behind the medical language. Osler's Textbook of Medicine ${ }^{1}$ became a foundation for medical education and practice in the early 20th century. As an internist at one of McGill's teaching hospitals, my father used "Osler" for his professional expertise; the textbooks of my mother, who became a pediatrician in the late 1920s, also used the vocabulary, grammar and language of Osler.

The physician is a professional, ${ }^{2}$ with expertise in a special area of knowledge. The physician is also a healer, caring for the patient who has the "dis-ease" and responding with compassion. When there is an imbalance between these 2 attributes, the physician's role is incomplete. As a medical resident, I was able to observe my parents' practice of medicine at first hand. They were healers as well as professionals. In the course of observing signs and symptoms, they took the time to listen carefully, and with the simple act of listening to the medical narrative, a process of healing had already begun. ${ }^{3}$ To put it another way, the importance of knowing the person with the disease was, for them, as important as knowing the disease the patient had.

Medicine has evolved into a fearsome knowledge- and technology-driven professionalism with enormous demands to know things, and equivalent pressures to shorten the time spent with the actual patient. Accordingly, it has become harder to be a healer while maintaining one's professionalism. Perhaps, with gains in knowledge and information, there has been a loss of wisdom. Have we become excellent technicians and fixers at the price of losing our ability or willingness to heal?

\section{The words we use}

In the aftermath of the Boer War (1899-1902), the British Army sought to enlist new soldiers and failed because the physical condition of eligible young men was so poor; the best had already been recruited. The state of the nation's health came as a shock, and the Maternal and Child Health Act was passed in 1904. Within a decade, childhood mortality and morbidity were declining (Fig. 1). ${ }^{4}$

The First World War gave a new vocabulary to medicine. Of the 4 million soldiers who lost their lives in the war, a great proportion died from disease rather than from violence. As disease itself became an identifiable enemy, so the language of the trenches transformed itself into medical metaphor. Diseases became killers, which we would crush and eradicate, along with the vermin in the trenches. From time to time breaktbroughs were made - if the problem was not entrenched. These words imply that the cause of disease is extrinsic to our bodies, but as metaphors they are out of date because the enemy, the cause of modern disease, is likely to be intrinsic, to reside within ourselves. The shift in the locus of cause in modern disease is a legacy of winning those earlier medical wars.

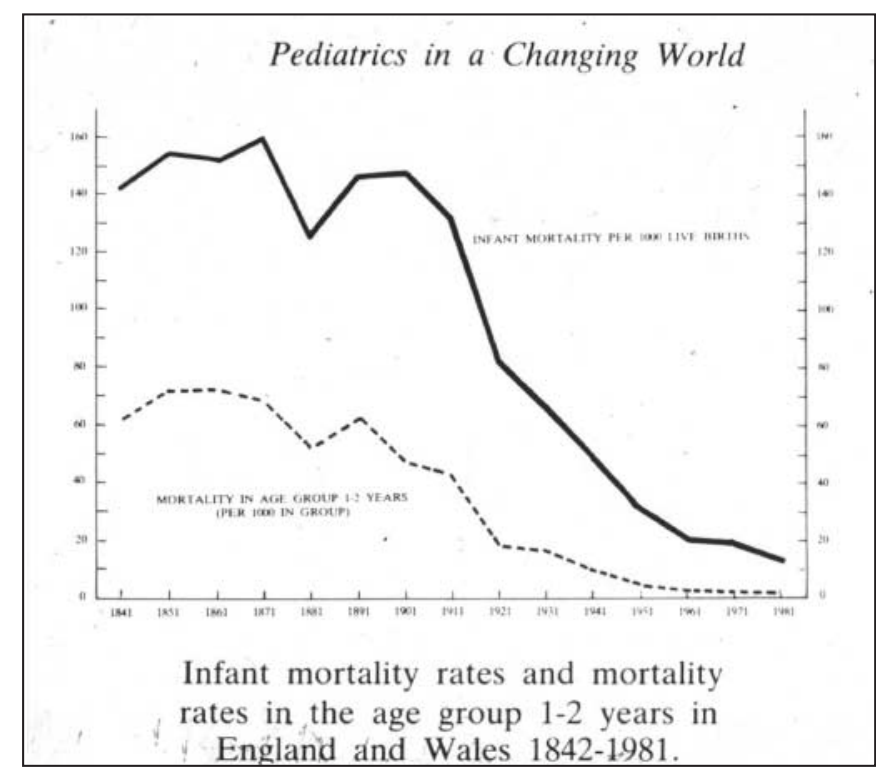

Fig. 1: The effect of an act of Parliament (1904) in the United Kingdom to improve maternal and child health. Reprinted with permission from reference 4 . 
When cause resides in experience, as in a communicable infection or a severe injury, it is an extrinsic cause, and it overwhelms the normal homeostatic processes of health. During the 20th century many such causes succumbed to better sanitation, better nutrition and prevention of accidents and injury, to campaigns of immunization and vaccination, and to antibiotics. The other type of cause is intrinsic - so-called noncommunicable disease. It may be an actual determinant of the disease (e.g., a rare mutation in a gene that functions as an essential component of a network) or it could be a variant of a gene (a polymorphism) that is prevalent in the population and confers susceptibility to disease under particular conditions of experience. Whatever the case, the intrinsic cause undermines (a good war word) homeostasis. For simplicity, we call these causes "genetic," meaning they change the constitutive biology of health. Genetic diseases are often prevalent, complex, multifactorial, polygenic and familial; they may also be rare, an orphan disease of penetrant Mendelian, or chromosomal, origin. Genetic disease collectively affects $5 \%$ of the population by age 25 , fills $50 \%$ of beds in pediatric hospitals such as mine, and affects at least $60 \%$ of citizens during their lifetime. ${ }^{5}$ Genetically caused diseases are personal illnesses.

The relative importance of extrinsic and intrinsic determinants of a disease in the population is summarized in a set of simple equations:

Let $\mathrm{P}=\mathrm{G}+\mathrm{E}$, where $\mathrm{P}$ is the phenotype or manifestation of a particular disease, with comorbidity due to $G$, a causal genotype, and E, a causal (environmental) experience. Since $\mathrm{P}$ will show a natural variation $(\mathrm{V})$ between people in the population with the particular disease, then $V_{P}=V_{G}+V_{E}$.

Now let $h^{2}$ be a symbol for broad-sense heritability of the disease in the population; $\mathrm{h}^{2}$ is the relative importance of the genetic contribution to its variation. Then, the equation is

$$
\text { heritability }\left(h^{2}\right)=\frac{V_{G}}{V_{P}}=\frac{V_{G}}{V_{G}+V_{E}}
$$

It follows that heritability of disease must rise when $V_{\mathrm{E}}$, the environmental causes, decline in prevalence. In other words, 100 years after measures were implemented to improve maternal and child health, disease in the population has become more individualized disease with intrinsic biological origins and with new relevance for diagnoses and treatments. Accordingly, a new set of medical metaphors is needed, along with a professionalism that accommodates the change. Moreover, when the so-called enemy is within us, the need for the physician to be a compassionate healer is ever most relevant.

\section{Evidence that heritability of disease can change}

Mortality and morbidity are highest in the life intervals covering embryonic and fetal life, infancy and childhood (Fig. 2). Only when the intervals of postreproductive aging and senescence are reached are mortality rates again com- parable. In the language of biology, death in the prereproductive life intervals is an "unnatural" death. If not the result of extrinsic harm, early death reflects natural selection. Accordingly, natural selection takes its highest toll in these early life intervals. The survivors are selected, by way of their adaptive biological attributes, to contribute to the gene pool of the next generation.

The homeostatic networks of living organisms confer metrical trait values with dispersion around the central tendency or the homing value. This is a fancy way of saying humankind has an optimal birth weight (Fig. 3). The frequency distribution of weight at birth is a familiar example. Birth weight is a selective trait. Rates of death are lowest when human birth weight is closest to the optimal value a process called stabilizing selection. Mean birth weight for human infants had not yet reached the optimal value when these data were obtained a generation ago, which implied that the process of stabilizing selection was still in progress. Pediatricians and newborn intensivists make enormous efforts to overcome the selective disadvantage conferred on very low birth-weight infants, which is often a result of assisted fertilization or other reproductive practices. Technology-driven initiatives to save these infants have become a form of directive selection that incur high associated risks for neurobehavioural dysfunction and reduced cognitive performance in later life. Furthermore, some forms of assisted fertilization have associated legacies of disrupted embryonic imprinting and a range of developmental disorders.

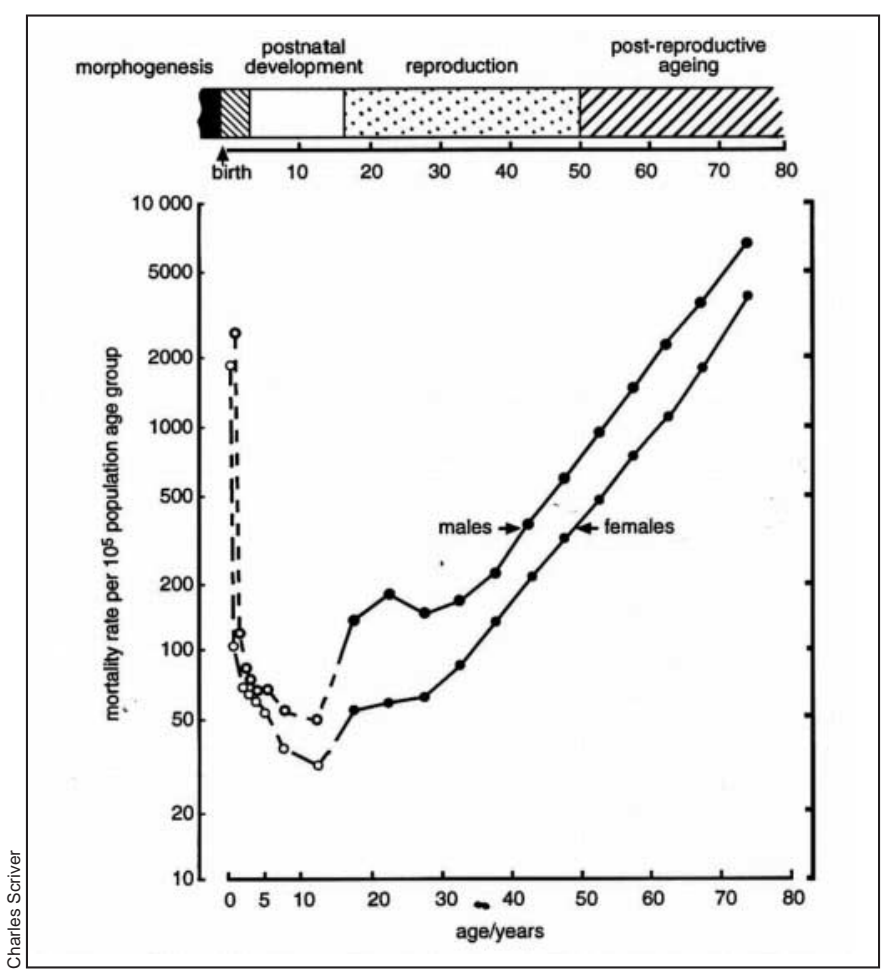

Fig. 2: Age-specific rates of death for males and females by 5year intervals, related to important human life intervals (see bar at top). Drawn using data from Statistics Canada, 1980. 
There are messages here: interventions in the embryonic and fetal stages of life, however humanely intended, may create costs to the child. Biological evolution had already found the optimal path for early human development; intrusions on it alter both the journey and the arrival.

The first-born child of John F. Kennedy died of respiratory distress syndrome (RDS). Such an event in a nation's first family can focus attention on a problem, as it did on RDS. Surfactant deficiency is the cause of RDS in most newborn infants, and research led to effective therapies involving surfactant supply at birth. By applying this new knowledge, mortality due to RDS fell from almost $100 \%$ to less than $10 \%$. Nonetheless, some full-term infants with RDS are resistant to treatment and have a fatal form of the disease; a positive family history is often present in these cases. Whereas RDS can largely be explained by immaturity in the development of lung and organism, the occurrence of familial RDS in full-term infants is likely to be something else. Indeed, these patients are likely to have an inborn error in the synthesis, storage, secretion, recycling or catabolism of surfactant as produced by the alveolar type II cells. ${ }^{6}$ These Mendelian disorders affect surfactant proteins $\mathrm{B}$ or $\mathrm{C}$ or the ATP-binding cassette transporter (ABCA3). The latter mediates targeting of surfactantcontaining vesicles to the lamellar bodies before secretion into alveoli where surfactant acts to reduce surface tension at the air-water interface. Mutations in the $A B C A 3$ gene are one cause of RDS in those few full-term infants who still manifest the disease. This is the molecular way of saying that heritability of RDS has increased while its incidence has declined over the past 4 decades.

The most prevalent causes of disease in human history have been environmental, largely nutritional and infective in

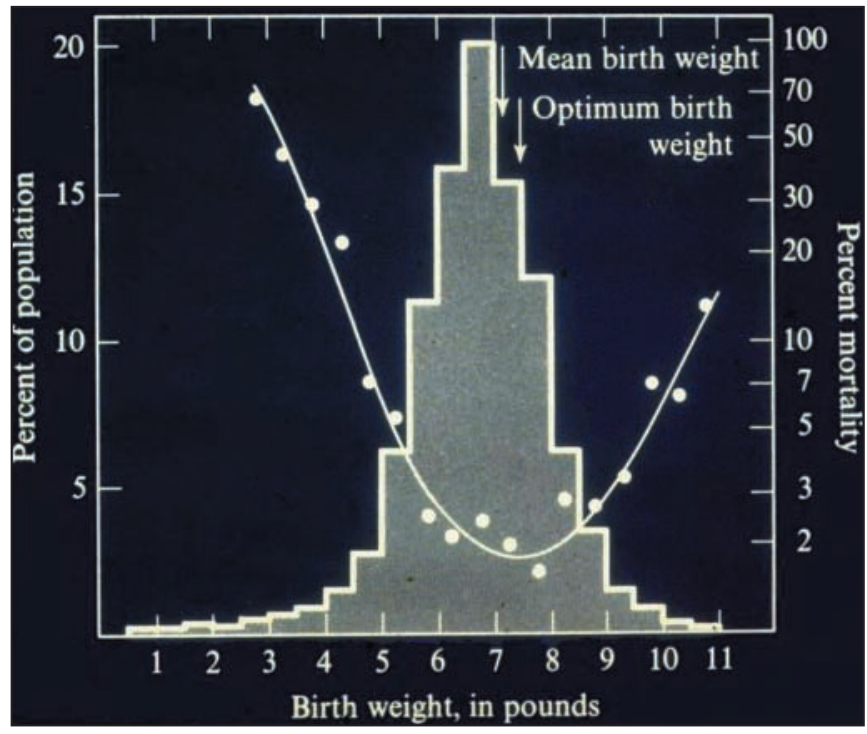

Fig. 3: A famous illustration of stabilizing selection in humans, showing the relation between rates of death at birth and birth weight. Source: Cavalli-Sforza LL and Bodmer WF, The genetics of human populations. San Francisco: WH Freeman; 1971. p. 613. origin. Rickets was a prevalent nutritional disease of modern infants and children living in the northern or temperate latitudes (Fig. 4). The incidence of nutritional rickets declined dramatically when relationships between ultraviolet radiation, vitamin $\mathrm{D}$ synthesis and bone mineralization were discovered. The discovery of vitamin D in the 1920s led to supplementation of infant diets; when this was done, rickets in the population at risk virtually disappeared. However, it did not disappear altogether. Cases with a new phenotype called "vitamin D resistant rickets" were heralded by a report in the pediatric literature of 1937. By the end of the 20th century, at least 5 Mendelian forms of infantile rickets due to hypophosphatemia, for example, had become known. There are corresponding genetic disorders of calcium and vitamin D metabolism. Thus, while the incidence of rickets was falling, its heritability in the pediatric population was increasing.

When the nature of the cause of disease changes, as it has in these 2 examples, this has implications for diagnosis, prevention and treatment and for the dosage and type of therapeutic agent in use. Medical education and practices are

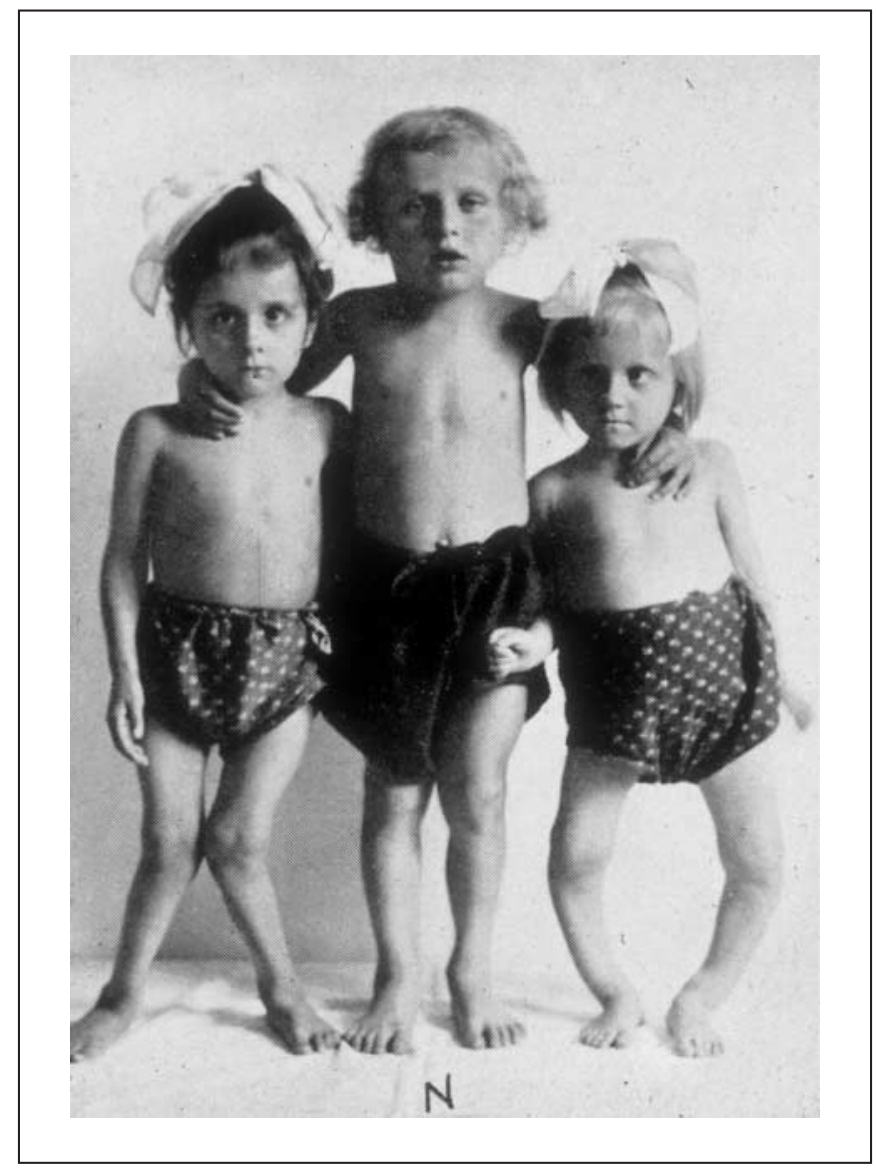

Fig. 4: A classic image of nutritional rickets in childhood. Applications of knowledge about the roles of sunlight and vitamin $\mathrm{D}$ in calcium homeostasis and bone mineralization changed the prevalence of the disease in the 20th century. The heritability of persisting cases would subsequently rise. From JB Scriver, source unknown. 
adapted accordingly. The magnitude of the challenge is recognized; it is difficult to know all the biological complexities of health and disease. Meanwhile, awareness of and respect for environmental causes of disease continues: obesity has become a major challenge to health and longevity across all age groups. By all measurements, this form of obesity has low heritability. Its principal causes appear to reside in culture and behaviour - in memes rather than in genes.

While the language of Osler, centred as it is on careful observations and descriptions of phenotypes, remains vital for the analysis of all disease types, the language can be expanded to include new ways of describing organisms. Some say it is becoming a world of "omes" (not the Buddhist mantra that invokes peace within ourselves, in others, and in all life forms), but the -omes of the genome world, with its epigenome, transcriptome, proteome and on out to the phenome and the environome.

\section{"I am a part of all that I have met" —Tennyson}

I belong to an extended family. I am person II-1 in the pedigree (Fig. 5). My niece by marriage, person III-12, developed a chronic pulmonary disease in her infancy, which my mother diagnosed as cystic fibrosis (CF). Jennifer died of the disease in her 20th year. Her unnatural death due to a natural disease still lingers in the collective memories of our family. In due course, my first-born daughter, III-2 in the pedigree, would use the knowledge derived from cloning the CFTR gene to reveal that she carried a CF-causing gene mutation and was herself at risk for having an affected child. Further investigations ruled out that possibility for the fetus she was carrying. Since then, other family members have sought mutation analysis and are being guided accordingly. Genetic thinking and analysis have been very relevant and helpful to our family.

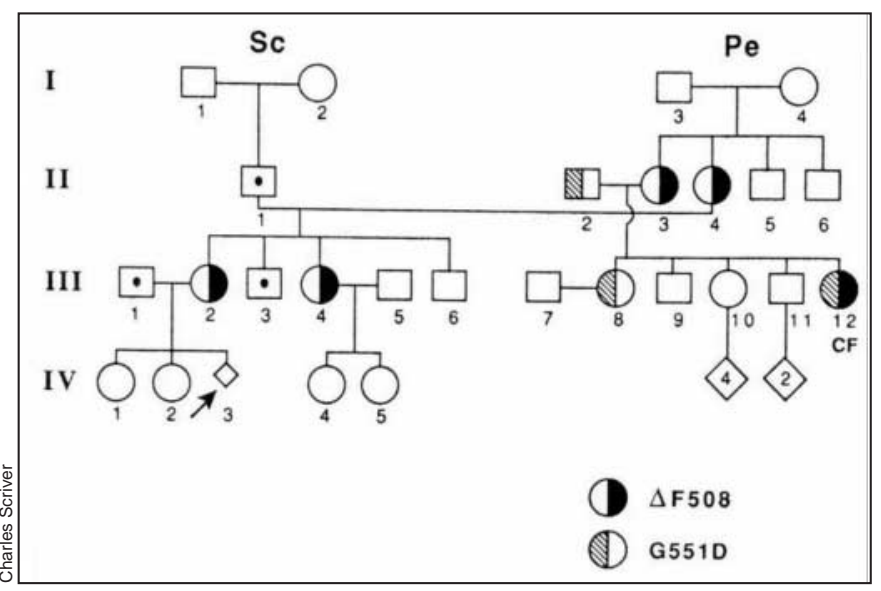

Fig. 5: My own nuclear and extended family. I am subject II-1. The pedigree diagram shows segregation of 2 different CFTR mutations. Subject III-13 died of cystic fibrosis. Fetus IV-3 was at risk for cystic fibrosis; accessible genomic information was used voluntarily here and at other times by family members in various ways to cope with risk for the disease. The open-square-with-dot symbol indicates people tested for cystic fibrosis mutations and found negative.

\section{Envoie}

Immanuel Kant asked, "What can I know, and with that knowledge, what ought I do?" To which I would add: "Who do I serve, and how do I serve?" Biology is a language that serves medicine, and it is becoming ever more relevant to know about genes: to know that they are digital information, are copied, that they function in the cells and bodies that are vehicles for passing them on. It is relevant to remember that every living person has ancestors who passed on his or her genes. ${ }^{8}$ It is also relevant to know that genetic variation itself is normal; it is dis-ease only when we experience it as illness. The professional will understand the process underlying the disease; the healer will alter the perception of illness. In the materialistic world of medicine, there is still a danger that we will lose the sense of wonder, become blind to the mysteries of life, or become intolerant of our diversity. A Russian poet, Osip Mandelstam, found a way to describe the wonder, the mystery and the diversity of Being. ${ }^{9}$

What shall I do with the body I have been given, So much at one with me, so much my own?

For the calm happiness of breathing, being able To be alive, tell me where I should be grateful.

I am gardener, flower too and un-alone In this vast dungeon.

My breath, my glow, you can already see On the windowpanes of eternity.

A pattern is imprinted there Unknown till now.

Let this muddle die down, this sediment flow out. The lovely pattern cannot be crossed out.

Charles Scriver is Alva Professor of Human Genetics, McGill University, Montréal, Que.

Acknowledgements: The influences of Richard and Sylvia Cruess at McGill University and of Don Boudreau's Task Force on Medical Education are apparent. Thoughts in the Presidential Address (1995) to the American Pediatric Society can also be recognized (Scriver CR. American Pediatric Society Presidential Address 1995: Disease, war, and biology: Languages for medicine - and pediatrics. Pediatr Res 1995;38:819-29). Perspectives on how the Human Genome Project could influence medicine (education and practice), long buried in an unpublished manuscript by Ken Flegel, Joan Matthews and Charles Scriver, are reincarnated here.

\section{References}

1. Osler W. The principles and practice of medicine. New York: D. Appleton and Company; 1892.

2. Cruess RL, Cruess SR, Johnston SE. Professionalism: an ideal to be sustained. Lancet 2000;356:156-9.

3. Charon R. Narrative and medicine. NEngl 7 Med 2004;350:862-4.

4. Forfar JO. Hutchison Memorial Lecture. Pediatrics in a changing world. International Child Health 1991;2(3):1-12.

5. Baird PA, Anderson TW, Newcombe HB, Lowry RB. Genetic disorders in children and young adults: a population study. Am 7 Hum Genet 1988;42:677-93.

6. Shulenin S, Nogee LM, Annilo T, Wert SE, Whitsett JA, Dean M. ABCA3 gene mutations in newborns with fatal surfactant deficiency. $N$ Engl 7 Med 2004;350;1296-303.

7. Albright F, Butler AM, Bloomberg E. Rickets resistant to Vitamin D therapy. Amer 7 Dis Child 1937;54:529-47.

8. Dawkins R. River out of Eden: a Darwinian view of life. London: Weidenfeld \& Nicolson; 1995.

9. Mandelstam O. Osip Mandelstam. J Greene, editor and translator. Boulder (CO): Shambhala; 1978. 